УДК 330.834

ББК 65.02(4Вел)

DOI 10.17150/2308-2588.2017.18(2).244-256

Е. А. Капогузов

Омский государственный университет им. Ф. М. Достоевского,

2. Омск, Российская Федерация

\title{
РОЛЬ КЕЙНСИАНСКИХ ИДЕЙ В ЭВОЛЮЦИИ ПАРАДИГМ ГОСУДАРСТВЕННОГО УПРАВЛЕНИЯ
}

\begin{abstract}
Аннотаиия. Теории Дж. М. Кейнса и его последователей, господствовавшие в экономической науке в 1930-1970-е гг., экономисты-неоклассики не без оснований уподобляют «ящику Пандоры». Ставшие популярными после возникновения концепции провалов рынка, они во многом определяли стратегию развития экономической политики, став нормативным оправданием как вмешательства государства в экономику, так и расширения роли государства. Именно под прикрытием кейнсианства в послевоенный период развертывалась «административная революция», происходило формирование идеологии
\end{abstract}


государственного дирижизма, что привело к усилению власти бюрократии в ущерб рыночным институтам. Хотя с 1970-е гг. кейнсианство перестало играть роль мейнстрима, однако влияние вульгаризированных кейнсианских идей и «простых» способов решения экономических проблем в условиях хронических бюджетных дефицитов и инфляции проявляется и в XXI веке.

Кююевые слова. Кейнсианство, теория общественного выбора, государственное регулирование экономики, бюрократия.

\section{E. A. Kapoguzov}

Dostoevsky Omsk State University, Omsk, Russian Federation

\section{THE ROLE OF KEYNESIAN IDEAS IN DEVELOPMENT OF THE GOVERNMENTAL MANAGEMENT PARADIGM}

Abstract. Neoclassic economists named the theories of John Maynard Keynes and his followers that dominated the economic theory in 1930es - 1970-es as Pandora's Box. The theory that became popular after emergence of the market failure conception determined the strategy of economic policy development and stimulated both acceleration of governmental intervention and increasing of the governmental role in the economy. Moreover, Keynesianism became a justification of introduction of «administrative revolution» and governmental «dirigisme» that lead to strengthening of the bureaucracy in the prejudice of market institutions. Although, after 1970-es Keynesianism lost its popularity, it still influences the processes of economic policy formation even in XXI century in condition of chronic budget deficit and inflation.

Keywords. Keynesianism, public choice theory, governmental management of the economy, bureaucracy.

Кейнсианская революция не была бы в полном смысле революцией, если бы не оказала многолетне- 
го воздействия на различные стороны общественной жизни. Хотя Кейнс настаивал, что его задача состоит в первую очередь в противопоставлении своих аргументов и выводов «аргументам и выводам классической теории, на которой я воспитывался и которая, как и 100 лет назад, господствует над практической и теоретической экономической мыслью правящих и академических кругов нашего поколения» [5, с. 224], влияние его книги и идей вышло далеко за пределы академических дискуссий.

Помимо влияния на развитие экономической науки, формирования по сути современной макроэкономики, идеи Кейнса оказали влияние на формирование идеологии государственного дирижизма, почва для которой успешно была подготовлена еще прогрессистским движением в США и, в некоторой степени, экономическими успехами СССР в период Великой депрессии. Основной характеристикой этого движения был рационализм, с новым пониманием целей государства. Оно должно было стать инструментом цивилизованности и гуманизма и активно способствовать общественному благосостоянию. Это означает обеспечение мира, порядка, социальной справедливости, воспитание молодежи, защиту от болезней и неопределенности и выравнивание коллективных групповых интересов. Государство должно взять на себя ответственность за достижение «лучшей жизни». Значительно больше, чем в либеральную эпоху, государство должно заниматься планированием и регулированием, особенно в таких сферах, как воспитание, здравоохранение, градостроительство и многих других сферах общественного интереса [2].

Сфера государственного управления, в рамках классического подхода не являющаяся в явном виде предметом подробного рассмотрения экономистов, под влиянием кейнсианства стала составной частью экономической науки, хотя и в более поздний период 
развития «узкой экономической теории бюрократии» [4]. В данной работе мы покажем, какие идеи Кейнса, представленные в «Общей теории занятости, процента и денег», способствовали расширению присутствия государства в экономике и формированию бюрократической парадигмы государственного управления, и как вульгаризация этих идей привела к будущему кризису кейнсианства в новых условиях воспроизводства.

Как отмечается в работе Дж. Бьюкенена и Р. Вагнера, в отличие от экономической теории кейнсианства, получившей широкое распространение в научной, образовательной и популярной литературе, кейнсианская экономическая политика получила лишь поверхностное освещение [11], хотя именно базовые положения кейнсианства определяли и определяют основные принципы экономической политики в западных странах после Второй мировой войны. Ставшая популярной после возникновения неоклассического синтеза концепция провалов рынка, она во многом определяла стратегию развития экономической политики, став нормативным оправданием как вмешательства государства в экономику, так и расширения роли государства.

С позиции Дж. М. Кейнса, большое значение имеет возможность обеспечения реализации эндогенной экономической политики. Как отмечается в главе 18 «Общей теории»: «Нашей конечной задачей является выбор тех переменных, которые могут находиться под сознательным контролем или управлением центральной власти в той реальной системе, в которой мы живем» [5, с. 415]. Речь идет в первую очередь о размерах совокупного спроса и национального дохода соответственно, влиять на который можно, прежде всего, через государственные закупки и инвестиции. Последним уделялась главенствующая роль с точки зрения акцентов и более простой организации инвестиционного процесса: «Я рассчитываю на то, что государство, 2017. T. 18, № 2. C. 244-256 
которое в состоянии взвесить предельную эффрективность капитальных благ с точки зрения длительных перспектив и на основе общих соииальных выгод, будет брать на себя все большую ответственность за прямую организацию инвестиций» (курсив мой. - Е. К.) [5, с. 351]. Вместе с тем, Кейнс рассматривал данную ситуацию в контексте ограниченности успеха чисто денежной политики, направленной на поощрение инвестиций. Но апологетам роста присутствия государства в экономике было удобно рассматривать государство как благонамеренного диктатора, обладающего совершенными (во всяком случае, по сравнению с субъектами частного бизнеса) прогностическими и вычислительными способностями, имеющим длительный горизонт планирования и движимым исключительно целью максимизации общественного благосостояния (социальной выгоды в приведенной цитате).

Кейнс пути решения проблем видел не только в расширении инвестиционной деятельности государства. В решении ключевой социальной проблема эпохи Великой депрессии - массовой безработицы - ему также представлялось невозможным справиться без участия государства. В этом случае придется буквально «наступать на горло» либеральным экономическим ценностям: «Поэтому, хотя расширение функций правительства в связи с задачей координации склонности к потреблению и побуждения инвестировать показалось бы публицисту XIX в. или современному американскому финансисту ужасающим покушением на основы индивидуализма, я, наоборот, защищаю его как единственное практически возможное средство избежать полного разрушения существующих экономических форм и как условие успешного функционирования личной инициативы» [5, с. 516].

Как известно, запоминается последнее. И в этом смысле последняя в «Общей теории» глава 24 «Заключительные замечания о социальной философии, 
к которой может привести общая теория» видится (пусть даже в вульгаризированной интерпретации) своеобразной апологетикой государственного вмешательства и райской музыкой для прогрессистских идей межвоенного периода. Как показывает Кейнс, «наиболее значительными пороками экономического общества, в котором мы живем, являются его неспособность обеспечить полную занятость, а также его произвольное и несправедливое распределение богатства и доходов» [5, с. 510]. Именно «мудрое и благоразумное государственное руководство», которое «должно дать возможность вести игру в соответствие с установленными правилами и ограничениями до тех пор, пока средний человек или хотя бы значительная часть общества остаются сильно подверженными страсти “делать деньги"» [5, с. 511].

Именно данные идеи и создают миф о кейнсианстве и учении Кейнса как о некоей антилиберальной альтернативе - вплоть до идеологической основы государственного капитализма (планово-рыночной модели) [2]. Вместе с тем сам Кейнс отрицал такой путь: «нет очевидных оснований для системы государственного социализма, который охватил бы большую часть экономической жизни общества» [5, с. 514]. Ведь даже в «современной классической теории обращается внимание на различные условия, в которых свободная игра экономических сил нуждается в обуздании и руководстве. Но все же остаются широкие возможности для проявления частной инициативы и ответственности» [5, с. 515]. Преимущества эффективности, личной заинтересованности, возможность личного выбора, которых люди лишены в гомогенном или тоталитарном государстве, по Кейнсу, также несомненны, а их отсутствие губительно.

В этой связи, уже после смерти Кейнса многие его идеи были неоднозначно истолкованы, что привело к различным ситуациям в сфере экономической поли2017. T. 18, № 2. C. 244-256 
тики. Одним из направлений для применения идей Кейнса к странам третьего мира стало использование кейнсианских рецептов в сфере экономической политики (теории «большого толчка» и др.) [8]. Между тем, то, как государство, вмешиваясь в экономическую систему, искажает систему традиционных ценностей и оказывает экономике «медвежью услугу», было показано Джеймсом Скоттом на многих примерах именно в странах третьего мира [10]. Мы же далее вернемся к сюжету о влиянии кейнсианских идей на развитие парадигм в сфере государственного управления.

К 1960-м годам кейнсианство становится ведущим течением в экономической политике, прежде всего в США. Как отмечает Х. Мински: «самопровозглашенные кейнсианцы стали важными правительственными консультантами и чиновниками в США. Они провозгласили решение проблемы цикличности как это было известно в истории. Они утверждали, что с помощью использования монетарной и фискальной политики экономика управляема с помощью режима тонкой настройки, что окончательно должно решить проблему рецессии и депрессии» [13, р. 161]. Тем самым государство становится ведущим агентом общественной жизни, а идеология дефицитного финансирования, неокейнсианский принцип акселератора и сверхмультипликатора, дополняющий кейнсианский мультипликатор, создавали основу для роста государственных расходов, расширения функций бюрократии.

В послевоенный период началось активное использование инструментария макрорегулирования и перераспределения. На основе теории провалов рынка возникли три базовые функции государства - аллокативная, дистрибутивная и стабилизирующая, представленные в работах как неокейнсианца П. Самуэльсона, так и одного из основателей теории государственных финансов Р. Масгрейва. Понимание бюрократии 
Р. Масгрейвом было идеалистичным. Бюрократ, по Р. Масгрейву, технократическая фигура, исполнитель воли общества. Хотя, с учетом все большего объема его функций, он скорее становится близок к гоббсовскому Левиафану, по мнению Масгрейва, с точки зрения его целевой функции, такой бюрократ - максимизирующий общественное благосостояние «социальный планировщик» (benevolent social planner), что отличает его от бьюкененовского бюрократа - максимизатора собственной выгоды [12].

Бюрократия рассматривается как механизм и инструмент реализации функций государства, предполагающий исполнение воли политиков, действующий в интересах общества, производящий общественные блага в рамках экзогенного бюджетного ограничения. Присутствие государства в экономике связано с необходимостью ликвидации провалов рынка (market failure), что аргументируется отклонением рынка от модели совершенной конкуренции, наличием асимметрии информации, внешних эффектов и монополизма. В этом случае бюрократия, являясь агентом государства по производству общественных благ, действует в интересах принципала (как непосредственного - политиков, так и конечного - общества), при стандартных неоклассических допущениях (в которые было интегрировано кейнсианство в результате неоклассического синтеза) о полноте и совершенстве информации, нулевых трансакционных издержках и полной рациональности субъектов.

Таким образом, кейнсианство стало открытием «ящика Пандоры» в части расширения как размеров государства [6], особенно после налоговой революции 1950-1960-х годов, так и его функций. Это способствовало росту бюрократии [1] и привело к возникновению государства Левиафана, зачастую неэффективного, с высоким уровнем государственного заимствования, провоцируемого существованием «фискальной иллю2017. T. 18, № 2. C. 244-256 
зии» и неспособного решить задачи постиндустриального развития.

Данная ситуация привела к системному кризису кейнсианства и неоконсервативной революции, с одной стороны, и, с другой стороны, к росту популярности неолиберальных идей, базирующихся на концепции «провалов государства» [9] и исходящих из иной поведенческой трактовки государства, чем это было в кейнсианстве и в рамках модели «благонамеренного диктатора», характерной для неоклассического синтеза.

На наш взгляд, ортодоксальная кейнсианская версия экономической политики, способствовавшая выходу из Великой депрессии и актуальная для соответствующей экономической ситуации, потеряла свою значимость в эпоху бюджетных дефицитов и структурных дисбалансов экономики, стала значимым элементом бюрократической парадигмы в государственном управлении [3]. Наиболее простые и вульгаризированные интерпретации кейнсианских идей привели к тому, что фискальная иллюзия, эффект храповика и политика дефицитного финансирования стали ее определяющими элементами. Самым простым способом решения экономических проблем стал бюрократический и экстенсивный - увеличение государственных расходов, вмешательство государства в экономику. Вместе с тем, после кризиса 1970-х гг. теоретические постулаты кейнсианства, продемонстрировав свою несостоятельность в новых условиях воспроизводства, подтолкнули к формированию новой, менеджеристской парадигмы, к широкому распространению реформ в сфере государственного управления [15]. Дефицит и кризис бюджетов привели как к сокращению расходов на государственное управление, так и к внедрению инструментов из частного сектора в практику управления общественным сектором. В результате, вместо неокейнсианских рецептов возник приоритет неолиберальных и неоконсервативных постулатов как 
в экономической политике, так и в практике государственного управления, в частности теории общественного выбора [7].

Это проявлялось, с одной стороны, в отказе от прогрессистской идеологии «чем больше государства, тем лучше». Как было показано У. Нисканеном, бюрократия склонна к перепроизводству, в связи с этим в сфере государственного управления возрастают неэффективные расходы, «строительство империй», система способствует информационной асимметрии, непрозрачности и недостаткам в контроле. Бороться с этим можно, вводя конкуренцию между бюрократами, предлагая потенциальные субституты на рынке. Также важно изменение структуры стимулов таким образом, чтобы вознаграждалось эффективное поведение. Ключевой пункт в подходе Нисканена - «чем меньше размер правительства, тем лучше» [14, р. 217]. Это объясняется тем, что бюрократия склонна к перепроизводству, в связи с этим административной системе свойственна тенденция к росту расходов, которая основывается на индивидуальном поведении и способствует информационной асимметрии, непрозрачности и недостаткам в контроле. Бороться с этим можно вводя конкуренцию между бюро, предлагая потенциальные субституты на рынке. Также важно изменение структуры стимулов таким образом, чтобы вознаграждалось эффективное поведение.

Решение проблем представители теории общественного выбора, в частности Г. Таллок видели в расчете и измерении издержек, путем внедрения квази-бухгалтерской техники, позволяющей условно оценить результаты. Идеальной была бы система индикаторов, оценивающая результат работы учреждения, но ее не всегда можно применить. В свою очередь, Э. Даунс предлагает альтернативный мотивационный механизм: бюрократическая идеология и этос. Идеология предполагает описание вклада учреждения в решение 2017. T. 18, № 2. C. 244-256 
общественных задач, демонстрация значимости функций бюро, прежде всего для политиков и общественности. Благодаря этосу возможно снизить оппортунизм за счет развития корпоративной культуры государственной службы, развития чувства принадлежности к решению значимых государственных задач и других элементов мотивации служения обществу.

Эта ветвь экономической теории бюрократии в рамках теории общественного выбора вызвала к жизни огромное количество публикаций, посвященных таким направлениям анализа бюрократии, как влияние групп специальных интересов (special interest groups), лоббизм и поиск ренты (rent seeking). Последнее связано с проблемой коррупции и само по себе является с теоретической и методологической стороны неисчерпаемой темой для анализа.

Критика теории общественного выбора направлена на основы государства благосостояния, разросшегося в связи с отсутствием конституционных ограничений до уровня Левиафана. Представители теории общественного выбора критиковали не только рост бюрократизации, но также растущую в обществе неэффективность и растраты ресурсов, что вызвано уже упомянутым выше открытием «ящика Пандоры» Кейнсом и его последователями.

Вместе с тем, господство вульгаризированных кейнсианских идей и простых способов решения экономических проблем в условиях хронических бюджетных дефицитов и инфляции проявляется и в XXI веке, что обнаруживается в политике «количественного смягчения», эмиссионного финансирования дефицита и расширения военных расходов. Ведь бюрократии значительно проще - чем повышать эффективность своей деятельности или проводить структурные и институциональные реформы - воспользоваться упрощенной версией кейнсианской концепции, о губительности чего предупреждал сам великий ученый: «...Идеи 
экономистов и политических мыслителей - и когда они правы, и когда они ошибаются - имеют гораздо большее значение, чем принято думать. В действительности только они и правят миром. Люди практики, которые считают себя совершенно не подверженными интеллектуальным влияния, обычно являются рабами какого-нибудь экономиста прошлого» [5, с. 518].

\section{Өписок использованной литературы}

1. Альпидовская М. Л. Бюрократия как социально-экономический институт / М. Л. Альпидовская. - М. : Красная звезда, 2006. - 87 с.

2. Дзарасов С. С. Куда Кейнс зовет Россию? / С. С. Дзарасов. - М. : Алгоритм, 2015. - 302, [1] с.

3. Капогузов Е. А. Институциональная структура производства государственных услуг : от веберианской бюрократии - к современным реформам государственного управления / Е. А. Капогузов. - Омск : Изд-во Омского государственного университета, 2012. - 399 с.

4. Капогузов Е. А. Расширенная экономическая теория бюрократии как теоретический фундамент реформирования государственного управления / Е. А. Капогузов // Ars Administrandi. - 2013. - № 2. - C. 5-18.

5. Кейнс Дж. М. Избранные произведения / Дж. М. Кейнс ; пер. с англ. [сост. А. Г. Худокормов; имен. указ., коммент. Ю. Н. Калашнов]. - М. : Экономика, 1993. - 540, [1] с.

6. Мюллер Д. Общественный выбор III / Д. Мюллер ; пер. с англ. под ред. А. П. Заостровцева, А. С. Скоробогатова. - М. : ГУ ВШЭ, 2007. - 1000, [1] с.

7. Нуреев Р. М. «Общая теория занятости, процента и денег» Дж. М. Кейнса: предпосылки возникновения, методология и особенности интерпретации / Р. М. Нуреев // Журнал институциональных исследований. - 2016. - Т. 8, № 1. - С. 6-35.

8. Нуреев Р. М. Экономика развития: модели становления рыночной экономики : учебник / Р. М. Нуреев. - 2-е изд., перераб. и доп. - М. : Норма, 2008. - 639 с.

9. Радыгин А. «Провалы государства»: теория и политика / А. Радыгин, Р. Энтов / / Вопросы экономики. - 2012. № 12. - C. 4-30.

10. Скотт Д. Благими намерениями государства : почему и какпроваливалисьпроектыулучшения условийчеловеч. жизни / Д. Скотт ; пер. с англ. - М. : Университет. кн., 2005. - 566, [2] с. 
11. Buchanan J. M. Democracy in Deficit: The Political Legacy of Lord Keynes / J. M. Buchanan, R. E. Wagner. - N.Y. : Academic Press, 1977. - 185 p.

12. Buchanan J. M. Public Finance and Public Choice : Two Contrasting Visions of the State / J. M. Buchanan, R. A. Musgrave. - Cambridge, Mass. : MIT Press, 1999. - 282 p.

13. Minsky H. P. John Maynard Keynes / H. P. Minsky. N. Y. : Columbia University Press, 1975. - xi, 181p.

14. Niskanen W. Bureaucracy and Representative Government / W. Niskanen. - Chicago ; N. Y. : Aldine-Atherton, 1971. - $232 \mathrm{p}$.

15. Pollitt C. Public Management Reform. A Comparative Analysis - New Public Management, Governance and the NeoWeberian State / C. Pollitt, G. Bouckaert. - 3d ed. - N.Y. : Oxford University Press, 2011. - 386 p.

\section{Информация об авторе}

Капогузов ЕВгений АлексееВич - доктор экономических наук, доцент, заведующий кафедрой экономической теории и предпринимательства, Омский государственный университет им. Ф. М. Достоевского, 644077, Россия, Омск, пр. Мира, 55a, e-mail: egenk@mail.ru.

\section{\&}

Evgeny A. Kapoguzov - D.Sc. in Economics, Associate Professor, Head of the Department of Economic Theory and Entrepreneurship, Dostoevsky Omsk State University, 55a, Mira pr., Omsk, 644077, Russian Federation, e-mail: egenk@mail.ru.

\section{Для цитирования}

Капогузов Е. А. Роль кейнсианских идей в эволюции парадигм государственного управления / Е. А. Капогузов / / Историко-экономические исследования. - 2017. - Т. 18, № 2. C. 244-256. - DOI: 10.17150/2308-2588.2017.18(2).244-256.

\section{$47: 4$.}

Kapoguzov E. A. The role of Keynesian ideas in development of the governmental management paradigm. Istoriko-ekonomicheskie issledovaniya $=$ Journal of Economic History $\mathcal{E}$ History of Economics, 2017, vol. 18, no. 2, pp. 244-256. DOI: 10.17150/23082588.2017.18(2).244-256. (In Russian). 